\title{
A FUZZY DEMATEL APPROACH FOR EVALUATING THE RISK FACTORS
}

\author{
(CASE STUDY: THE INSTRUCTION CENTER OF IRAN'S NATIONAL OIL \\ COMPANY)
}

\author{
Mohammad-Bagher Fakhrzad*i, Mohammad-Reza Firozpour and \\ HASAN HOSSEINI NASAB
}

\begin{abstract}
Many risk factors are dependent on each other and taking this into account can be helpful in managing appropriate decisions. The poor evaluation of these factors will impose high costs in many real applications especially for a supply chain. There are different methods for risk evaluating and their effects for ranking them. For instant, in fuzzy DEMATEL method, the experts' linguistic opinions and preferences on the agent effects are used as the input. The important point is how these opinions are aggregated to produce less computational error. In this regard, this paper proposes a new method based on statistical inferences for a fuzzy DEMATEL approach for evaluating the factors of a supply chain. This method was applied to a case study and the results showed that the proposed method was better than other methods for integrating the experts' opinions in a supply chain. However, this method was proposed for the evaluation of supply chain factors, it can be applied to other systems as well.
\end{abstract}

Mathematics Subject Classification. 62A86, 91G70.

Received July 6, 2020. Accepted July 21, 2021.

\section{INTRODUCTION}

Many factors such as international competitors, demanding customers and rapid technological change profoundly impact the markets. Therefore, successful competition in this environment requires reducing operational costs and enlarging profit margins. For most industrial firms, the purchasing of raw material and component parts from suppliers constitutes a major expense. Hence, among the various strategic activities involved in the supply chain management, the purchase decision has profound impacts on the overall system [34]. When supply chain is faced with risk events, selecting the right suppliers becomes more essential than ever for the business. Several factors such as unquantifiable information, incomplete information, unobtainable information and partial ignorance cause the imprecision in decision making. Since conventional MADM methods cannot effectively handle problems with such imprecise information, therefore fuzzy multiple attribute decision-making methods have been developed owing to the imprecision in assessing the relative importance of attributes and the performance ratings of alternatives with respect to attributes [10]. Decision-Making Trial and Evaluation Laboratory (DEMATEL) is a widely used method to analyze and visualize the structure of complex systems through

Keywords. Supply chain, fuzzy DEMATEL, experts' linguistic preferences, agent ranking.

Department of Industrial Engineering, Yazd University, Yazd, Iran.

*Corresponding author: mfakhrzad@yazd.ac.ir 
matrices and digraphs. The method typically requires dealing with substantial uncertainties and subjectivities inherent in the judgment process. A review of the literature shows that several extensions of DEMATEL have been suggested so far dealing with a variety of sources of uncertainty. However, the uncertainty originating from the human doubt that might arise in the assignment of membership degrees during the assessments is partly or entirely ignored in these studies [1]. The decision-making trial and evaluation laboratory (DEMATEL) method is a hot issue in industrial engineering field for it can help determine critical factors in complex system. Although lots of efforts have been spent on improving the DEMATEL, they are just the extensions from the subjective perspective but lack of the objective perspective [7]. However, the crisp values sometimes cannot reflect human thinking comprehensively [35]. To address this problem, the -maker's DMs preferences were measured using fuzzy membership degrees [41]. However, in general, the estimation of experts' opinions using exact numerical values, especially in terms of uncertainty, is highly challenging. This is because decision making results are severely dependent upon inaccurate and ambiguous subjective judgments. This factor has led to the need to fuzzy logic DEMATEL. As a result, in DEMATEL, type-2 fuzzy linguistic variables are used, and this can facilitate decision-making under environmental uncertainty conditions [8]. The literature shows that in reflecting the linguistic preferences fuzzy numbers are more powerful than crisp numbers. However, it is not clear that which method can make less computational error in aggregating the experts' opinions. In this paper, a mathematical and statistical based method is proposed such that we have a more suitable method for aggregating the experts' opinions and preferences in fuzzy DEMATEL method.

In this paper, first the literature on supply chain, DEMATEL method, the theory of fuzzy systems, and Fuzzy DEMATEL are investigated. Then in the following, the research method and proposed method for transforming the experts' opinions in fuzzy DEMATEL method has been explained. Moreover, the proposed method is applied to a case study. The paper is concluded in last section.

\section{Subject Literature}

From the literature, the following can be referred to:

\subsection{Supply chain and its influential and influenced factors}

The complexities in present day supply chain are numerous and are evolving due to globalization, customization, innovation, flexibility, sustainability and uncertainties. The growing supply chain complexity results in negative consequences on cost, customer service and reputation. Managing supply chain complexity without compromising the profitability is a challenging task. Supply chain complexity (SCC) management involves identifying, prioritizing, measuring, analyzing and controlling/eliminating the drivers of complexity. The SCC drivers denote number and variety of suppliers, customers, products, processes and uncertainties which are highly interdependent. Firms need to prioritize the drivers in order to manage and simplify SCC [21]. Thus identifying all the complexity drivers and their interrelations that lead to unpredictable outcomes in supply chain is the first step in managing the complexity. Firms within supply chain are interested to address the dominant drivers rather than addressing all the drivers [11].

\subsection{DEMATEL method}

Decision-making trial and evaluation laboratory (DEMATEL) has been widely used in decision-making methods with the aim of discovering the relations among the criteria in complex and intertwined problems. DEMATEL method is capable of analyzing the total relations among sets of variables using the mathematical techniques adopted to obtain logical relationships and direct impact of relationships [23]. Decision-making trial and evaluation laboratory method) DEMATEL) is known as a powerful approach to sum up experts' opinions about a problem and utilize them to solve complex and multifaceted problems [5, 25]. DEMATEL method, originally developed by Battelle Memorial Institute to search for integrated solutions [12], is one of the methods used to visualize the structure of causal relationships among factors in an understandable manner. It can transfer the cause-effect relations among factors into a comprehensive model to aid the process of decision making. 
DEMATEL is one the effective technique to find and analyses the inter-relationship among the system factors. This method transforms the causal relationships between the factors indicators into a tangible structural model. DEMATEL is a comprehensive method for the preparation and analysis of a structural model that includes causal relationships between complex factors. This technique acts on directional graphs, and these graphs are able to display directional relationships between sub-systems. The result of the DEMATEL technique is to divide the factors into two cause and effect groups [30]. A review of the literature shows that the most common theories used to model uncertainty inherent in the assessment process and analysis are ordinary fuzzy set theory [38], intuitionistic fuzzy set (IFS) theory [14], type-2 fuzzy set theory [8], evidence theory [42], grey theory $[37,40]$ and 2-tuple fuzzy linguistic representation [24,32]. According to the review of the literature, the most widely studied approach considering uncertainty in DEMATEL is based on ordinary fuzzy sets. In order to model uncertainty inherent in the assessment process, the fuzzy approach uses linguistic terms and corresponding predefined functions with varying membership grades (typically triangular or trapezoidal fuzzy numbers). This allows dealing with vague and/or ambiguous expressions and judgments of experts.

\subsection{The fuzzy system theory}

Implementing fuzzy sets in decision making problems represents an important and efficient application compared to classical set theory. Fuzzy logic is the one that replaces the conclusion methods in human brain to express ambiguity in the form of a number. It introduces a function for the membership in one group that assigns a number between zero and one to every element. This number represents the level of the element's membership in the set. Zero indicates that the element is totally outside the set while one means the element is completely in the set [3]. In numerous real life situations, the judgments of decisionmakers are normally characterized by ambiguity. Fuzzy numbers are suggested to suitably express linguistic variables. The triangular and trapezoidal fuzzy numbers have identified most commonly used fuzzy numbers [27]. In this method, sharp numerical values are represented as bands of fuzzy numbers with an overlap [2]. In such cases, the use of a definitive scoring system can be criticized for two reasons; first, definitive methods ignore ambiguity resulting from people's judgment and may not be able to convert the changes in linguistic terms into numbers. Secondly, selecting priorities based on people's subjective judgments can largely influence the results [9]. Fuzzy logic is a useful tool for measuring ambiguous concepts related to individual subjective judgment and is a powerful method to overcome the above-mentioned problems [20].

\subsection{Fuzzy DEMATEL}

The main advantage of FDEMATEL is to consider the fuzziness and to provide flexibility in a fuzzy environment [4]. Therefore, prior to giving the details of FDEMATEL method, it requires to mention some preliminaries of fuzzy set theory and important notations. Fuzzy set theory reflects the uncertainties that result from vague and imprecise linguistic expressions [20]. Fuzzy DEMATEL method is currently applied in many areas such as management $[17,28]$, emergency planning [22], health care systems [31,36], and safety management $[5,15]$. The overview of the literature show that for integrating the experts' opinions and preferences in DEAMTEL, arithmetic mean has been usually used [26,29]. Since arithmetic mean is sensitive to outliers, the integration of experts' opinions using this method has high error. Thus, a new method is proposed here through which different methods for the integration of opinions can be evaluated so that the most suitable one is selected.

\section{THE RESEARCH METHOD}

\subsection{Fuzzy sets}

Definition 3.1. Figure 1 shows a triangular fuzzy number $(\widetilde{M})$ and parameters $(l, m, u)$ such that $l$ is the smallest possible occurrence value, $m$ is the most probable value, and $u$ is the largest possible occurrence value. 


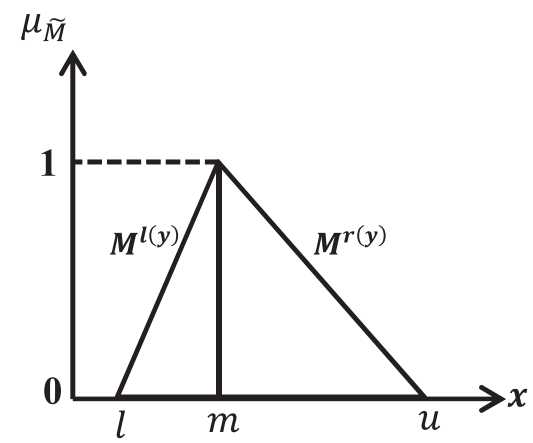

Figure 1. A triangular fuzzy number.

The left and right sides of each fuzzy number can be linearly determined by the following membership function:

$$
\mu_{F(x)}=\left\{\begin{array}{ll}
0 & x \leq l \\
\frac{x-l}{m-l} & l<x \leq m \\
\frac{u-x}{u-m} & m<x \leq u \\
0 & x>u
\end{array} .\right.
$$

Definition 3.2. The following equation shows how a triangular fuzzy number can be represented by the degree of its left and right membership $(l(y)$ is the degree of left membership and $r(y)$ is the degree of right membership).

$$
\widetilde{M}=\left(M^{l(y)}, M^{r(y)}\right)=[l+(m-l) y, u-(u-m) y], \quad y \in[0,1] .
$$

Definition 3.3. The mathematical equations for two triangular fuzzy numbers $\widetilde{M}_{1}=\left(l_{1}, m_{1}, u_{1}\right)$ and $\widetilde{M}_{2}=$ $\left(l_{2}, m_{2}, u_{2}\right)$ are defined as follows:

$$
\begin{aligned}
\widetilde{M}_{1}+\widetilde{M}_{2} & =\left(l_{1}+l_{2}, m_{1}+m_{2}, u_{1}+u_{2}\right) \\
\widetilde{M}_{1}-\widetilde{M}_{2} & =\left(l_{1}-u_{2}, m_{1}-m_{2}, u_{1}-l_{2}\right) \\
\widetilde{M}_{1} \times \widetilde{M}_{2} & =\left(l_{1} \times l_{2}, m_{1} \times m_{2}, u_{1} \times u_{2}\right) \\
k \times \widetilde{M}_{1} & =\left(k \times l_{1}, k \times m_{1}, k \times u_{1}\right) \\
\frac{\widetilde{M}_{1}}{k} & =\left(\frac{l_{1}}{k}, \frac{m_{1}}{k}, \frac{u_{1}}{k}\right), \quad(k>0) .
\end{aligned}
$$

Definition 3.4. The following relation converts a fuzzy number to a Crisp number:

$$
\operatorname{Crisp}\left(\widetilde{M}_{1}\right)=\frac{l_{1}+2 m_{1}+u_{1}}{4}
$$

\subsection{Fuzzy DEMATEL}

The fuzzy DEMATEL algorithm is executed in the following steps.

Step 1. The experts express their judgments in linguistic scale. Some linguistic scales of the literature that are changed to triangular fuzzy number (TFN) are shown in Table 1:

Step 2. The fuzzy initial direct-relation matrix is defined as follows:

$$
\widetilde{Z}_{k}=\left(\widetilde{z}_{i j k}\right)_{n \times n}=\left(\left(l_{i j k}, m_{i j k}, u_{i j k}\right)\right)_{n \times n}
$$


TABLE 1. The linguistic scale and corresponding TFNs.

\begin{tabular}{llll}
\hline \hline \multirow{2}{*}{ Linguistic scale } & \multicolumn{3}{c}{ References } \\
\cline { 2 - 4 } & {$[4,13,16,18,19,26,29,39]$} & {$[33]$} & {$[31]$} \\
\cline { 2 - 4 } & TFN & TFN & TFN \\
\hline No influence (NO) & $(0,0,0.25)$ & $(0,0.1,0.3)$ & $(0,0.01,0.3)$ \\
Very Low influence (VL) & $(0,0.25,0.5)$ & $(0.1,0.3,0.5)$ & $(0.2,0.3,0.5)$ \\
Low influence (L) & $(0.25,0.5,0.75)$ & $(0.3,0.5,0.7)$ & $(0.3,0.5,0.7)$ \\
High influence (H) & $(0.5,0.75,1)$ & $(0.5,0.7,0.9)$ & $(0.5,0.7,0.9)$ \\
Very High influence (VH) & $(0.75,1,1)$ & $(0.7,0.9,1)$ & $(0.7,0.9,1)$ \\
\hline
\end{tabular}

where $\widetilde{z}_{i j k}$ shows the judgment of expert $k$ on the impact of factor $i$ on factor $j$. Therefore, the fuzzy initial direct-relation matrix is as follows.

$$
\widetilde{Z}_{k}=\left(\widetilde{z}_{i j k}\right)_{n \times n}=\left[\begin{array}{cccc}
0 & \widetilde{z}_{12 k} & \cdots & \widetilde{z}_{1 n k} \\
\widetilde{z}_{21 k} & 0 & & \widetilde{z}_{2 n k} \\
\vdots & & \ddots & \vdots \\
\widetilde{z}_{n 1 k} & \widetilde{z}_{n 2 k} & \cdots & 0
\end{array}\right] .
$$

Step 3. In this step, the judgments of $k$ experts are aggregated. The review of the literature shows that most of the researchers have used average method for aggregating the judgments [6, 26, 29, 31, 33, 39]. This forms the average matrix $\widetilde{Z}$ as the following:

$$
\widetilde{Z}=\left(\widetilde{z}_{i j}\right)_{n \times n}=\left(\left(\frac{\widetilde{z}_{i j 1} \oplus \widetilde{z}_{i j 2} \oplus \ldots \oplus \widetilde{z}_{i j k}}{k}\right)\right)_{n \times n}
$$

Step 4. The fuzzy normalized direct-relation matrix $\widetilde{X}$ is calculated.

$$
\widetilde{X}=\left(\widetilde{x}_{i j}\right)_{n \times n}=\left[\begin{array}{cccc}
\widetilde{x}_{11} & \widetilde{x}_{12} & \ldots & \widetilde{x}_{1 n} \\
\widetilde{x}_{21} & \widetilde{x}_{22} & & \widetilde{x}_{2 n} \\
\vdots & \ddots & \vdots \\
\widetilde{x}_{n 1} & \widetilde{x}_{n 2} & \cdots & \widetilde{x}_{n n}
\end{array}\right]
$$

where $\widetilde{x}_{i j}=\frac{\widetilde{z}_{i j}}{r}=\left(\frac{l_{i j}}{r}, \frac{m_{i j}}{r}, \frac{u_{i j}}{r}\right) ; r=\max _{1 \leq i \leq n}\left(\sum_{j=1}^{n} u_{i j}\right)$.

Step 5. Consider $\widetilde{X}=\left(\widetilde{x}_{i j}\right)_{i j}=\left(l_{i j}^{\prime}, m_{i j}^{\prime}, u_{i j}^{\prime}\right)_{i j}$ where $X_{l}=\left(l_{i j}^{\prime}\right)_{n \times n}, X_{m}=\left(m_{i j}^{\prime}\right)_{n \times n}, X_{u}=\left(u_{i j}^{\prime}\right)_{n \times n}$. The elements of these matrices are extracted from $\widetilde{X}$ as follows:

$$
\begin{gathered}
X_{l}=\left[\begin{array}{cccc}
0 & l_{12}^{\prime} & \cdots & l_{1 n}^{\prime} \\
l_{21}^{\prime} & 0 & & l_{2 n}^{\prime} \\
\vdots & \ddots & \vdots \\
l_{n 1}^{\prime} & l_{n 2}^{\prime} & \cdots & 0
\end{array}\right] \\
X_{m}=\left[\begin{array}{cccc}
0 & m_{12}^{\prime} & \ldots & m_{1 n}^{\prime} \\
m_{21}^{\prime} & 0 & & m_{2 n}^{\prime} \\
\vdots & & \ddots & \vdots \\
m_{n 1}^{\prime} & m_{n 2}^{\prime} & \cdots & 0
\end{array}\right] \\
X_{u}=\left[\begin{array}{cccc}
0 & u_{12}^{\prime} & \cdots & u_{1 n}^{\prime} \\
u_{21}^{\prime} & 0 & & u_{2 n}^{\prime} \\
\vdots & \ddots & \vdots \\
u_{n 1}^{\prime} & u_{n 2}^{\prime} & \cdots & 0
\end{array}\right] .
\end{gathered}
$$


Step 6. The fuzzy total relation matrix $\widetilde{T}$ is obtained as follows:

$$
\begin{aligned}
& \widetilde{T}=\lim _{k \rightarrow \infty}\left(\widetilde{X}^{1}+\widetilde{X}^{2}+\ldots+\widetilde{X}^{k}\right) \\
& \widetilde{T}=\left[\begin{array}{cccc}
\widetilde{t}_{11} & \widetilde{t}_{12} & \ldots & t_{1 n} \\
\widetilde{t}_{21} & \widetilde{t}_{22} & & t_{2 n} \\
\vdots & \ddots & \vdots \\
\widetilde{t}_{n 1} & \widetilde{t}_{n 2} & \cdots & \widetilde{t}_{n n}
\end{array}\right] \\
& \widetilde{t}_{i j}=\left(l_{i j}^{\prime \prime}, m_{i j}^{\prime \prime}, u_{i j}^{\prime \prime}\right)
\end{aligned}
$$

where $\left[l_{i j}^{\prime \prime}\right]=X_{l} \times\left(I-X_{l}\right)^{-1},\left[m_{i j}^{\prime \prime}\right]=X_{m} \times\left(I-X_{m}\right)^{-1},\left[u_{i j}^{\prime \prime}\right]=X_{u} \times\left(I-X_{u}\right)^{-1}$.

Step 7. The non-fuzzy total relation matrix is obtained as follows:

$$
t_{i j}=\frac{\left(l_{i j}^{\prime \prime}+2 m_{i j}^{\prime \prime}+u_{i j}^{\prime \prime}\right)}{4} .
$$

Step 8. The experts should identify a threshold value $(\alpha)$ to filter out some negligible casual relationships. If $t_{i j} \geq \alpha$, then element $i$ has a significant causal relationship on element $j$.

Step 9. The values of the matrices $D$ and $R$, where $D$ is the sum of columns and $R$ is the sum of rows of matrix $T$, are obtained (they represents the influence on and the relationships with others):

$$
\begin{aligned}
& T=\left(t_{i j}\right)_{n \times n}, i, j \in\{1,2, \ldots, n\} \\
& D=\left(\sum_{j=1}^{n} t_{i j}\right)_{n \times 1}=\left(t_{i}\right)_{n \times 1} \\
& R=\left(\sum_{i=1}^{n} t_{i j}\right)_{1 \times n}^{t}=\left(t_{j}\right)_{n \times 1} .
\end{aligned}
$$

Some criteria have positive values of $D-R$ and therefore greatly influence other criteria. These criteria are called dispatchers; others have negative values of $D-R$ and thus are greatly influenced by other criteria. These are called receivers. The value of $D+R$ indicates the degree of relationship between each criterion with other criteria. Criteria having greater values of $D+R$ have stronger relationships with other criteria, while those having smaller values of $D+R$ have less of a relationship with others.

Step 10. Using values of $D+R$ and $D-R$, make an impact relationship chart that shows the causal relationships of the elements.

\subsection{ANOVA (ANALYSIS OF VARIANCE)-MANOVA (MULTIVARIATE ANALYSIS OF VARIANCE)}

Hypothesis testing for a single variable, such as the $t$-test and $Z$-test, are used for testing one or two samples in a univariate case, while in a case with several variables (the multivariate case), Hotelling's test ( $T^{2}$ ) is used. These tests cannot be used for three or more samples. Thus a new technique should be considered for this purpose. Analysis of variance (ANOVA) for one dependent variable and a multivariate analysis of variance (MANOVA) for several dependent variables measured on each sampling unit will be used to test the equality of means for three or more samples. ANOVA can be used in the case of two means (two samples), and the results will be the same as the $Z$ or $t$ tests. Assumptions of ANOVA:

(1) Normality: the samples must be selected from populations that are normally or approximately normally distributed.

(2) Independence: the samples must be independent.

(3) Homogeneity: the variances of the populations must be equal. 


\section{One-way ANOVA}

It considers only one independent variable $(X)$ (called a factor) at $g$ levels (groups), and the objective is to study the effect of different levels of the factor on a continuous response $(Y)$. In a one-way ANOVA, researchers are interested in testing the following hypotheses:

$$
\left\{\begin{array}{l}
H_{0}: \mu_{1}=\mu_{2}=\ldots=\mu_{n} \\
H_{1}: \mu_{i} \neq \mu_{j} \text { for at least one pair }(i, j), i=1,2, \ldots, n .
\end{array}\right.
$$

\section{Two-way ANOVA}

The idea of one-way analysis of variance can be extended to include two independent variables (factors); each variable has at least two levels and one response variable. The technique for analyzing the effect of two independent variables is called a two-way analysis of variance. Suppose there are two factors, factor $A$ at $g$ levels and factor $B$ at $q$ levels. The researchers are interested in testing the following hypotheses.

Hypothesis about the effect of the first factor (factor $A$ ):

$$
\left\{\begin{array}{l}
H_{0}: \alpha_{1}=\alpha_{2}=\ldots=\alpha_{g}=0 \\
H_{1}: \text { at least one } \alpha_{i} \neq 0, i=1,2, \ldots, g
\end{array}\right.
$$

Hypothesis about the effect of the second factor (factor $B$ ):

$$
\left\{\begin{array}{l}
H_{0}: \beta_{1}=\beta_{2}=\ldots=\beta_{q}=0 \\
H_{1}: \text { at least one } \beta_{j} \neq 0, j=1,2, \ldots, q .
\end{array}\right.
$$

Hypothesis about the effect of interaction between the two factors $A$ and $B$ :

$$
\left\{\begin{array}{l}
H_{0}:(\alpha \beta)_{i j}=0 \\
H_{1}: \text { at least one }(\alpha \beta)_{i j} \neq 0 .
\end{array}\right.
$$

\section{MULTIVARIATE ANALYSIS OF VARIANCE (MANOVA)}

The idea of a multivariate analysis of variance (MANOVA) is the same as a univariate analysis of variance (ANOVA), because both methods are used to test the equality of means for three or more samples. However, the difference between ANOVA and MANOVA is that ANOVA is used when only one response variable (dependent variable) is measured for each experimental unit, while MANOVA is used when several response variables (dependent variables) are measured for each experimental unit. Assumptions for MANOVA:

(1) Normality: the samples must be selected from populations that are normally or approximately normally distributed.

(2) Independence: the samples must be independent.

(3) Homogeneity: all populations have a common variance-covariance matrix.

(4) Multivariate normal: each population is multivariate normally distributed.

\section{One-way MANOVA}

The concept of one-way MANOVA is the same as one-way ANOVA, and the difference between them is the number of response variables (dependent variables). In a multivariate case, there are $g$ populations, and the objective is to compare these populations based on several measurements (dependent variables), i.e., whether the $g$ samples' mean vectors are the same or not. In a one-way MANOVA, the researchers are interested in the following hypothesis (a sample with size of $n$ is from $k$-variate normal populations with equal covariance matrices):

$$
\left\{\begin{array}{c}
H_{0}: \mu_{1}=\left[\begin{array}{c}
\mu_{11} \\
\mu_{12} \\
\vdots \\
\mu_{1 k}
\end{array}\right] \\
H_{1}: \text { at least two } \mu \text { 's are different } \\
\mu_{2 k}
\end{array}\right]=\mu_{2}=\left[\begin{array}{c}
\mu_{21} \\
\mu_{22} \\
\vdots \\
\mu_{g k}
\end{array}\right]
$$


where, $\mu$ is a vector.

If the null hypothesis is not rejected, the $g$ means are equal for each dependent variable, while rejecting the null hypothesis means that at least two means (groups) differ for at least one dependent variable.

\section{Two-way MANOVA}

Suppose there are two factors: factor $A$ has a levels and factor $B$ has $b$ levels. The objective is to investigate the effect of different levels of each factor on several responses measured on the same experimental unit. In a two-way multivariate analysis of variance (MANOVA), the researchers are interested in three hypotheses the first two hypotheses are related to the main effect of each factor and the third hypothesis is related to the interaction between the different levels of factor $A$ and factor $B$. The hypotheses for interaction and main effects can be tested by using the Wilk's test.

\section{Proposed method}

As was said in step 3 of Section 3.2, in DEMATEL method, the aggregated matrix is obtained by combining the experts' opinions and preferences. In the literature, most of the studies have used arithmetic mean. However, this method is drastically sensitive to outliers. That is, the incorrect judgment of one or a few experts may affect the aggregated matrix of the judgments and increase the computational error. Taking this into account, this paper proposes a method that, among different aggregation methods, can identify the proper one for each case study.

\subsection{The fuzzy initial direct-relation matrix}

The steps 1 and 2 are the same as the general fuzzy DEMATEL explained in Section 3.2. So, the fuzzy initial direct-relation matrix is shown as follows:

$$
\widetilde{Z}_{k}=\left(\widetilde{z}_{i j k}\right)_{n \times n}=\left(\left(l_{i j k}, m_{i j k}, u_{i j k}\right)\right)_{n \times n}=\left[\begin{array}{cccc}
0 & \widetilde{z}_{12 k} & \cdots & \widetilde{z}_{1 n k} \\
\widetilde{z}_{21 k} & 0 & \cdots & \widetilde{z}_{2 n k} \\
\vdots & \ddots & \vdots \\
\widetilde{z}_{n 1 k} & \widetilde{z}_{n 2 k} & \cdots & 0
\end{array}\right]
$$

where $\widetilde{z}_{i j k}$ represents the judgment of expert $k$ on the impact of factor $i$ on factor $j$.

\subsection{Methods for aggregating the experts' judgments of step 3}

4.2.1. Conventional method (CM): average of experts' judgments

$$
\widetilde{Z}=\left(\widetilde{z}_{i j}\right)_{n \times n}=\left(\left(\frac{\widetilde{z}_{i j 1} \oplus \widetilde{z}_{i j 2} \oplus \ldots \oplus \widetilde{z}_{i j k}}{k}\right)\right)_{n \times n}=\left(l_{i j}, m_{i j}, u_{i j}\right)_{n \times n} .
$$

\subsubsection{The proposed methods for aggregating experts' judgments}

The first method (FM): Min $l_{i j k}$-Average $m_{i j k}$-Max $u_{i j k}$

$$
\widetilde{Z}=\left(\widetilde{z}_{i j}\right)_{n \times n}=\left(\left\{\min \left(l_{i j 1}, l_{i j 2}, \ldots, l_{i j k}\right)\right\},\left\{\left(\frac{\sum m_{i j k}}{k}\right)\right\},\left\{\max \left(u_{i j 1}, u_{i j 2}, \ldots, u_{i j k}\right)\right\}\right)_{n \times n} .
$$

The second method (SM): Modified averages

$$
\widetilde{Z}=\left(\widetilde{z}_{i j}\right)_{n \times n}=\left(\left\{\frac{\sum l_{i j n^{\prime}}}{k^{\prime}} \mid n^{\prime} \in\left(\forall l_{i j k}<m_{i j}\right)\right\}, m_{i j},\left\{\frac{\sum u_{i j n^{\prime \prime}}}{k^{\prime \prime}} \mid n^{\prime \prime} \in\left(\forall u_{i j k}>m_{i j}\right)\right\}\right)_{n \times n}
$$

where $m_{i j}=\left(\frac{\sum m_{i j k}}{k}\right), k^{\prime}$ is the number of experts, so that the values of $l_{i j k}$ are less than $m_{i j}$, and $k^{\prime \prime}$ is the number of experts, so that the value of $u_{i j k}$ is more than $m_{i j}$. 
TABle 2. The Fuzzy DEMATEL outputs with regard to different methods of aggregating experts' judgments.

\begin{tabular}{lllllllll}
\hline \hline \multirow{2}{*}{$\begin{array}{l}\text { Important factors in } \\
\text { supply chain }\end{array}$} & \multicolumn{8}{c}{ Methods for aggregating experts' judgments } \\
& \multicolumn{9}{c}{ CM } & \multicolumn{7}{c}{ FM } & \multicolumn{3}{c}{ SM } & \multicolumn{2}{c}{ TM } \\
\cline { 2 - 9 } & $D+R$ & $D-R$ & $D+R$ & $D-R$ & $D+R$ & $D-R$ & $D+R$ & $D-R$ \\
\hline F1 & $A_{11}$ & $B_{11}$ & $A_{12}$ & $B_{12}$ & $A_{13}$ & $B_{13}$ & $A_{14}$ & $B_{14}$ \\
F2 & $A_{21}$ & $B_{21}$ & $A_{22}$ & $B_{22}$ & $A_{23}$ & $B_{23}$ & $A_{24}$ & $B_{24}$ \\
$\vdots$ & $\vdots$ & $\vdots$ & $\vdots$ & $\vdots$ & $\vdots$ & $\vdots$ & $\vdots$ & $\vdots$ \\
Fn & $A_{n 1}$ & $B_{n 1}$ & $A_{n 2}$ & $B_{n 2}$ & $A_{n 3}$ & $B_{n 3}$ & $A_{n 4}$ & $B_{n 4}$ \\
\hline
\end{tabular}

The third method (TM): interval confidence

$$
\widetilde{Z}=\left(\widetilde{z}_{i j}\right)_{n \times n}=\left(m_{i j}-3 S_{l_{i j}}, m_{i j}, m_{i j}+3 S_{u_{i j}}\right)_{n \times n}
$$

where $m_{i j}=\left(\frac{\sum m_{i j k}}{k}\right), S_{l_{i j}}=\frac{\sum\left(l_{i j}-l_{i j k}\right)^{2}}{k-1}, l_{i j}=\left(\frac{\sum l_{i j k}}{k}\right), S_{u_{i j}}=\frac{\sum\left(u_{i j}-u_{i j k}\right)^{2}}{k-1}$ and $u_{i j}=\left(\frac{\sum u_{i j k}}{k}\right)$.

Note: if $m_{i j}-3 S_{l_{i j}}<0$ then $m_{i j}-3 S_{l_{i j}}=0$ and if $m_{i j}+3 S_{u_{i j}}>1$ then $m_{i j}+3 S_{u_{i j}}=1$.

\subsection{The steps 4-10 are the same with the general fuzzy DEMATEL explained in Section 3.2}

\subsection{The comparison of the improved fuzzy DEMATEL to different methods of aggregating experts' judgments}

Each one of the methods given in Section 4.2 for integrating experts' opinions have different outputs in terms of $D+R$ and $D-R$ values for important factors of a supply chain (Tab. 2). These two values depend on one subject (the method of aggregating experts' opinions). Thus, we use one-way MANOVA to evaluate the aggregation method.

In One-way MANOVA, the hypothesis for Table 2 is expressed as follows:

$$
\left\{\begin{array}{l}
H_{0}: \mu_{\mathrm{CM}}=\left[\begin{array}{l}
\mu_{D+R} \\
\mu_{D-R}
\end{array}\right]=\mu_{\mathrm{FM}}=\left[\begin{array}{l}
\mu_{D+R} \\
\mu_{D-R}
\end{array}\right]=\mu_{\mathrm{SM}}=\left[\begin{array}{l}
\mu_{D+R} \\
\mu_{D-R}
\end{array}\right]=\mu_{\mathrm{TM}}=\left[\begin{array}{l}
\mu_{D+R} \\
\mu_{D-R}
\end{array}\right] \\
H_{1}: \text { at least two } \mu \text { 's are different. }
\end{array}\right.
$$

If the null hypothesis is rejected, it means that there is a significant difference between the aggregation methods. In this case, the most appropriate method can be selected using the other tests of one-way MANOVA.

\section{Case Study}

To evaluate the proposed method, a case study is presented here. The training supply chain of Iranian national oil company includes the training centers of the company, different companies, both internal and external, that provide training materials, training units of different oil companies covered by Iranian national oil company as the distributor of the training courses, and all employees of Iranian national oil company as those who receive these trainings. Accordingly, Mahmoudabad oil training center was selected as our case study.

\subsection{Mahmoudabad oil training center}

It is Located on the coasts of Mazandaran Sea with an area of 26 hectares. It has around $28000 \mathrm{~m}^{2}$ of training and dormitory area. The center was established in January 1985 to train the experts required in the oil industry. 
The training center had 19 years of academic activity starting in January 1985 in associate degree and bachelor's degree in mechanic, electricity, electronic, gas supply and petro chemistry. Then in Since July 2003 hitherward, the Center joined the Human Resource Development of the National Iranian Oil Co. with a mission to provide the training needed by experts and managers and recruiting in the oil industry.

\subsubsection{Vision statement}

Turning the center to an active leading focal point in training and consultation in oil industry in Iran and in the region and gaining professional recognition at international level is our goal.

\subsubsection{Mission statement}

- The center renders sophisticated training and consultation services adapted to suit the needs of companies affiliated the ministry of oil.

- The center is committed to satisfy and increase the number of its customers and constantly improve its efficiency while maintaining the prevalent values and regulations.

\subsection{The key factors in Mahmoudabad training center}

Based on the conducted studies, customers, processes, and financial factors are so critical for this center that each one has been divided into multiple sub-factors, described in the following.

Customers factors $(\mathrm{C})$ :

- Promoting the marketing system (C1).

- Attracting new customers and enhancing the market share (C2).

- Increasing customer satisfaction and making loyal customers (C3).

- Fulfilling the needs of managers and experts and carrying out constant research on training needs analysis and needs creation $(\mathrm{C} 4)$.

- Concentrating on the services to be provided to individuals and organizations and promoting the cultural level of families (C5).

- Increasing diversity, distinctiveness and outsourcing (C6).

- Increasing productivity and empowerment of the center staffs $(\mathrm{C} 7)$.

Processes factors $(\mathrm{P})$ :

- Promoting infrastructure and tools and improving procedures (P1).

- Improving and upgrading training quality (P2).

- Developing and networking joint scientific cooperation with other reliable domestic and international companies and institutes (P3).

- Cooperating with various section in the oil industry with an aim to improve management and engineering systems and methods (P4).

Financial factors $(\mathrm{F})$ :

- Increasing sales and the value added (F1).

- Managing costs by focusing on priorities (F2).

\subsection{Evaluating of factors with proposed method}

To assess how influential these factors are and how they are influenced, a questionnaire was designed and sent for 50 experts of this field. They were asked to express their opinion in linguistic scale as no influence (NO), very low (VL), Low (L), high (H), and very high (VH) influence (Tab. 3). From these, 38 questionnaires were completed and returned.

These linguistic scales are transformed to triangular fuzzy number (TFN) as in Table 4:

Accordingly, the fuzzy initial direct-relation matrix for expert 1 is shown in Table 5 . 
TABLE 3. The judgments in linguistic scale for expert 1.

\begin{tabular}{llllllllllllll}
\hline \hline Expert 1 & C1 & C2 & C3 & C4 & C5 & C6 & C7 & P1 & P2 & P3 & P4 & F1 & F2 \\
\hline C1 & 0 & VH & H & VH & H & VH & H & L & L & VH & H & VH & H \\
C2 & H & 0 & L & VH & H & VH & H & L & H & H & VH & VH & VH \\
C3 & L & VH & 0 & H & H & VL & L & H & L & L & H & VH & H \\
C4 & L & VH & H & 0 & L & VH & H & VH & VH & H & H & VH & H \\
C5 & H & H & L & L & 0 & H & VL & VL & NO & L & L & L & L \\
C6 & L & H & VL & H & VL & 0 & L & L & H & L & H & H & L \\
C7 & VH & VH & VH & H & L & L & 0 & VH & VH & VH & H & H & H \\
P1 & L & VH & VH & H & L & L & H & 0 & VH & L & L & H & H \\
P2 & H & VH & VH & H & L & L & H & H & 0 & L & L & VH & H \\
P3 & H & H & VH & VH & L & L & H & VH & VH & 0 & H & H & L \\
P4 & H & H & H & VH & L & L & H & VH & VH & L & 0 & H & L \\
F1 & VL & L & L & L & H & L & H & H & H & H & H & 0 & H \\
F2 & VL & L & L & L & H & L & H & H & H & H & L & H & 0 \\
\hline
\end{tabular}

TABLE 4. The relationship between linguistic scales and fuzzy numbers.

\begin{tabular}{ll}
\hline \hline Linguistic scale & Triangular Fuzzy Number (TFN) \\
\hline No influence (NO) & $(0,0,0.25)$ \\
Very Low influence (VL) & $(0,0.25,0.5)$ \\
Low influence (L) & $(0.25,0.5,0.75)$ \\
High influence (H) & $(0.5,0.75,1)$ \\
Very High influence (VH) & $(0.75,1,1)$ \\
\hline
\end{tabular}

TABLE 5. The fuzzy initial direct-relation matrix for expert 1.

\begin{tabular}{|c|c|c|c|c|c|c|c|}
\hline Expert 1 & $\mathrm{C} 1$ & $\mathrm{C} 2$ & C3 & $\mathrm{C} 4$ & C5 & $\mathrm{C} 6$ & $\mathrm{C} 7$ \\
\hline $\mathrm{C} 1$ & $(0,0,0)$ & $(0.75,1,1)$ & $(0.5,0.75,1)$ & $(0.75,1,1)$ & $(0.5,0.75,1)$ & $(0.75,1,1)$ & $(0.5,0.75,1)$ \\
\hline $\mathrm{C} 2$ & $(0.5,0.75,1)$ & $(0,0,0)$ & $(0.25,0.5,0.75)$ & $(0.75,1,1)$ & $(0.5,0.75,1)$ & $(0.75,1,1)$ & $(0.5,0.75,1)$ \\
\hline C3 & $(0.25,0.5,0.75)$ & $(0.75,1,1)$ & $(0,0,0)$ & $(0.5,0.75,1)$ & $(0.5,0.75,1)$ & $(0,0.25,0.5)$ & $(0.25,0.5,0.75)$ \\
\hline $\mathrm{C} 4$ & $(0.25,0.5,0.75)$ & $(0.75,1,1)$ & $(0.5,0.75,1)$ & $(0,0,0)$ & $(0.25,0.5,0.75)$ & $(0.75,1,1)$ & $(0.5,0.75,1)$ \\
\hline C5 & $(0.5,0.75,1)$ & $(0.5,0.75,1)$ & $(0.25,0.5,0.75)$ & $(0.25,0.5,0.75)$ & $(0,0,0)$ & $(0.5,0.75,1)$ & $(0,0.25,0.5)$ \\
\hline C6 & $(0.25,0.5,0.75)$ & $(0.5,0.75,1)$ & $(0,0.25,0.5)$ & $(0.5,0.75,1)$ & $(0,0.25,0.5)$ & $(0,0,0)$ & $(0.25,0.5,0.75)$ \\
\hline $\mathrm{C} 7$ & $(0.75,1,1)$ & $(0.75,1,1)$ & $(0.75,1,1)$ & $(0.5,0.75,1)$ & $(0.25,0.5,0.75)$ & $(0.25,0.5,0.75)$ & $(0,0,0)$ \\
\hline $\mathrm{P} 1$ & $(0.25,0.5,0.75)$ & $(0.75,1,1)$ & $(0.75,1,1)$ & $(0.5,0.75,1)$ & $(0.25,0.5,0.75)$ & $(0.25,0.5,0.75)$ & $(0.5,0.75,1)$ \\
\hline $\mathrm{P} 2$ & $(0.5,0.75,1)$ & $(0.75,1,1)$ & $(0.75,1,1)$ & $(0.5,0.75,1)$ & $(0.25,0.5,0.75)$ & $(0.25,0.5,0.75)$ & $(0.5,0.75,1)$ \\
\hline P3 & $(0.5,0.75,1)$ & $(0.5,0.75,1)$ & $(0.75,1,1)$ & $(0.75,1,1)$ & $(0.25,0.5,0.75)$ & $(0.25,0.5,0.75)$ & $(0.5,0.75,1)$ \\
\hline $\mathrm{P} 4$ & $(0.5,0.75,1)$ & $(0.5,0.75,1)$ & $(0.5,0.75,1)$ & $(0.75,1,1)$ & $(0.25,0.5,0.75)$ & $(0.25,0.5,0.75)$ & $(0.5,0.75,1)$ \\
\hline F1 & $(0,0.25,0.5)$ & $(0.25,0.5,0.75)$ & $(0.25,0.5,0.75)$ & $(0.25,0.5,0.75)$ & $(0.5,0.75,1)$ & $(0.25,0.5,0.75)$ & $(0.5,0.75,1)$ \\
\hline F2 & $(0,0.25,0.5)$ & $(0.25,0.5,0.75)$ & $(0.25,0.5,0.75)$ & $(0.25,0.5,0.75)$ & $(0.5,0.75,1)$ & $(0.25,0.5,0.75)$ & $(0.5,0.75,1)$ \\
\hline
\end{tabular}

The fuzzy initial direct-relation matrix was calculated for all of the experts. For aggregating the experts' opinions, the conventional method $(\mathrm{CM})$ and the proposed methods of this research have been used (Tabs. 6-9).

The remaining of the calculations were done using fuzzy DEMATEL. The remarkable note for the case study is that in the proposed FM method $\left(I-X_{u}\right)^{-1}$ is undefined, and consequently, $\left[u_{i j}^{\prime \prime}\right]=X_{u} \times\left(I-X_{u}\right)^{-1}$ is not defined. Therefore, this method cannot be used in the case study. The values for $D+R$ and $D-R$ for each one Tables 6,8 , and 9 are reported in Table 10 . 
TABLE 5. continued.

\begin{tabular}{llllll}
\hline \hline P1 & P2 & P3 & P4 & F1 & F2 \\
\hline$(0.25,0.5,0.75)$ & $(0.25,0.5,0.75)$ & $(0.75,1,1)$ & $(0.5,0.75,1)$ & $(0.75,1,1)$ & $(0.5,0.75,1)$ \\
$(0.25,0.5,0.75)$ & $(0.5,0.75,1)$ & $(0.5,0.75,1)$ & $(0.75,1,1)$ & $(0.75,1,1)$ & $(0.75,1,1)$ \\
$(0.5,0.75,1)$ & $(0.25,0.5,0.75)$ & $(0.25,0.5,0.75)$ & $(0.5,0.75,1)$ & $(0.75,1,1)$ & $(0.5,0.75,1)$ \\
$(0.75,1,1)$ & $(0.75,1,1)$ & $(0.5,0.75,1)$ & $(0.5,0.75,1)$ & $(0.75,1,1)$ & $(0.5,0.75,1)$ \\
$(0,0.25,0.5)$ & $(0,0,0.25)$ & $(0.25,0.5,0.75)$ & $(0.25,0.5,0.75)$ & $(0.25,0.5,0.75)$ & $(0.25,0.5,0.75)$ \\
$(0.25,0.5,0.75)$ & $(0.5,0.75,1)$ & $(0.25,0.5,0.75)$ & $(0.5,0.75,1)$ & $(0.5,0.75,1)$ & $(0.25,0.5,0.75)$ \\
$(0.75,1,1)$ & $(0.75,1,1)$ & $(0.75,1,1)$ & $(0.5,0.75,1)$ & $(0.5,0.75,1)$ & $(0.5,0.75,1)$ \\
$(0,0,0)$ & $(0.75,1,1)$ & $(0.25,0.5,0.75)$ & $(0.25,0.5,0.75)$ & $(0.5,0.75,1)$ & $(0.5,0.75,1)$ \\
$(0.5,0.75,1)$ & $(0,0,0)$ & $(0.25,0.5,0.75)$ & $(0.25,0.5,0.75)$ & $(0.75,1,1)$ & $(0.5,0.75,1)$ \\
$(0.75,1,1)$ & $(0.75,1,1)$ & $(0,0,0)$ & $(0.5,0.75,1)$ & $(0.5,0.75,1)$ & $(0.25,0.5,0.75)$ \\
$(0.75,1,1)$ & $(0.75,1,1)$ & $(0.25,0.5,0.75)$ & $(0,0,0)$ & $(0.5,0.75,1)$ & $(0.25,0.5,0.75)$ \\
$(0.5,0.75,1)$ & $(0.5,0.75,1)$ & $(0.5,0.75,1)$ & $(0.5,0.75,1)$ & $(0,0,0)$ & $(0.5,0.75,1)$ \\
$(0.5,0.75,1)$ & $(0.5,0.75,1)$ & $(0.5,0.75,1)$ & $(0.25,0.5,0.75)$ & $(0.5,0.75,1)$ & $(0,0,0)$ \\
\hline
\end{tabular}

TABLE 6. The aggregation of the experts' judgments with the conventional CM manner in fuzzy DEMATEL.

\begin{tabular}{llllllll}
\hline \hline \multicolumn{2}{l}{$\mathrm{C} 1$} & $\mathrm{C} 2$ & $\mathrm{C} 3$ & $\mathrm{C} 4$ & $\mathrm{C} 5$ & $\mathrm{C} 6$ & $\mathrm{C} 7$ \\
\hline $\mathrm{C} 1$ & $(0,0,0)$ & $(0.63,0.88,1)$ & $(0.35,0.5,0.73)$ & $(0.38,0.63,0.85)$ & $(0.35,0.58,0.83)$ & $(0.45,0.7,0.9)$ & $(0.23,0.43,0.68)$ \\
C2 & $(045,0.65,0.88)$ & $(0,0,0)$ & $(0.2,033,0.58)$ & $(0.4,0.58,0.73)$ & $(0.38,0.58,0.8)$ & $(0.4,0.63,0.83)$ & $(0.35,0.55,0.78)$ \\
C3 & $(0.43,0.68,0.9)$ & $(0.65,0.9,1)$ & $(0,0,0)$ & $(0.43,0.68,0.88)$ & $(0.3,0.55,0.78)$ & $(0.25,0.48,0.73)$ & $(0.33,0.55,0.8)$ \\
C4 & $(0.58,083,0.95)$ & $(0.63,0.83,1)$ & $(0.58,0.78,0.98)$ & $(0,0,0)$ & $(0.43,068,0.88)$ & $(0.45,0.68,0.88)$ & $(0.48,0.73,0.9)$ \\
C5 & $(0.35,0.55,0.78)$ & $(0.5,0.75,0.95)$ & $(0.48,0.73,0.95)$ & $(0.43,0.68,0.9)$ & $(0,0,0)$ & $(0.28,0.45,0.7)$ & $(0.43,0.65,0.85)$ \\
C6 & $(0.38,0.63,0.85)$ & $(0.58,0.83,1)$ & $(0.35,0.58,0.8)$ & $(0.38,0.58,0.8)$ & $(0.25,0.43,0.68)$ & $(0,0,0)$ & $(0.33,0.55,0.8)$ \\
C7 & $(0.5,0.73,0.9)$ & $(0.63,0.88,0.98)$ & $(0.6,0.85,0.98)$ & $(0.55,0.8,0.98)$ & $(0.38,0.63,0.83)$ & $(0.3,0.55,0.78)$ & $(0,0,0)$ \\
P1 & $(0.45,0.68,0.9)$ & $(0.6,0.85,1)$ & $(0.68,0.93,1)$ & $(0.45,0.68,0.9)$ & $(0.28,0.45,0.7)$ & $(0.38,0.6,0.83)$ & $(0.48,0.7,0.9)$ \\
P2 & $(0.48,0.73,0.95)$ & $(0.68,0.93,1)$ & $(0.6,0.85,1)$ & $(0.53,0.78,0.98)$ & $(0.43,0.68,0.9)$ & $(0.45,0.7,0.9)$ & $(0.5,0.75,0.98)$ \\
P3 & $(0.55,0.8,1)$ & $(0.6,0.85,1)$ & $(0.5,0.75,0.9)$ & $(0.5,0.73,0.88)$ & $(0.33,0.53,0.75)$ & $(0.48,0.73,0.95)$ & $(0.48,0.7,0.88)$ \\
P4 $(0.48,0.73, .098)$ & $(0.63,0.86,1)$ & $(0.55,0.8,1)$ & $(0.53,0.78,0.95)$ & $(0.4,0.65,0.88)$ & $(0.5,0.75,0.95)$ & $(0.48,0.7,0.9)$ \\
F1 & $(0.5,0.73,0.88)$ & $(0.45,0.68,0.85)$ & $(0.5,0.73,0.88)$ & $(0.38,0.5,0.75)$ & $(0.43,0.65,0.88)$ & $(0.4,0.63,0.83)$ & $(0.45,0.65,0.83)$ \\
F2 & $(0.35,0.58,0.78)$ & $(0.3,0.53,0.78)$ & $(0.3,0.5,0.75)$ & $(0.3,0.48,0.73)$ & $(0.33,0.5,0.75)$ & $(0.28,0.5,0.75)$ & $(0.33,0.53,0.75)$ \\
\hline
\end{tabular}

TABLE 6. continued.

\begin{tabular}{lllllll}
\hline \hline \multicolumn{2}{l}{ P1 } & P2 & P3 & P4 & F1 & F2 \\
\hline C1 & $(0.3,0.53,0.78)$ & $(0.28,0.5,0.75)$ & $(0.53,0.78,0.95)$ & $(0.43,0.65,0.9)$ & $(0.6,0.85,0.98)$ & $(0.33,0.58,0.83)$ \\
C2 & $(0.35,0.55,0.78)$ & $(0.48,0.73,0.98)$ & $(0.53,0.78,0.95)$ & $(0.55,0.8,0.95)$ & $(0.68,0.93,1)$ & $(0.5,0.73,0.88)$ \\
C3 & $(0.38,0.63,0.85)$ & $(0.45,0.7,0.9)$ & $(0.38,0.6,0.83)$ & $(0.38,0.58,0.83)$ & $(0.58,0.83,1)$ & $(0.4,0.63,0.88)$ \\
C4 & $(0.5,0.75,0.93)$ & $(0.53,0.78,0.95)$ & $(0.45,0.7,0.93)$ & $(0.5,0.75,0.95)$ & $(0.6,0.85,1)$ & $(0.5,0.75,0.95)$ \\
C5 & $(0.33,0.55,0.8)$ & $(0.48,0.7,0.9)$ & $(0.4,0.65,0.9)$ & $(0.45,0.7,0.9)$ & $(0.55,0.8,0.95)$ & $(0.38,0.6,0.85)$ \\
C6 & $(0.33,0.55,0.8)$ & $(0.4,0.65,0.9)$ & $(0.38,0.6,0.83)$ & $(0.4,0.63,0.83)$ & $(0.48,0.73,0.95)$ & $(0.35,0.58,0.8)$ \\
C7 & $(0.48,0.7,0.9)$ & $(0.58,0.83,0.98)$ & $(0.5,0.75,0.93)$ & $(0.43,0.68,0.9)$ & $(0.55,0.8,0.98)$ & $(0.43,0.68,0.93)$ \\
P1 & $(0,0,0)$ & $(0.63,0.88,1)$ & $(0.5,0.73,0.9)$ & $(0.53,0.78,0.98)$ & $(0.55,0.8,0.98)$ & $(0.48,0.73,0.95)$ \\
P2 & $(0.5,0.75,0.98)$ & $(0,0,0)$ & $(0.43,0.65,0.88)$ & $(0.58,0.83,0.98)$ & $(0.55,0.8,0.98)$ & $(0.48,0.73,0.95)$ \\
P3 & $(0.53,0.78,0.93)$ & $(0.6,0.85,1)$ & $(0,0,0)$ & $(0.55,0.8,0.98)$ & $(0.5,0.75,0.95)$ & $(0.38,0.6,0.83)$ \\
P4 & $(0.55,0.8,0.93)$ & $(0.63,0.88,0.98)$ & $(0.5,0.75,0.95)$ & $(0,0,0)$ & $(0.5,0.73,0.83)$ & $(0.4,0.65,0.88)$ \\
F1 & $(0.5,0.73,0.93)$ & $(0.53,0.75,0.9)$ & $(0.5,0.73,0.88)$ & $(0.4,0.63,0.85)$ & $(0,0,0)$ & $(0.45,0.68,0.83)$ \\
F2 & $(0.33,0.48,0.7)$ & $(0.38,0.63,0.88)$ & $(0.25,0.45,0.7)$ & $(0.25,0.48,0.73)$ & $(0.38,0.58,0.8)$ & $(0,0,0)$ \\
\hline
\end{tabular}


TABLE 7. The aggregation of the experts' judgments with the proposed FM manner in fuzzy DEMATEL.

\begin{tabular}{llllllll}
\hline \hline \multicolumn{2}{l}{ C1 } & C2 & C3 & C4 & C5 & C6 & C7 \\
\hline C1 & $(0,0,0)$ & $(0.5,0.88,1)$ & $(0,0.5,1)$ & $(0,0.63,1)$ & $(0, .58,1)$ & $(0.25,0.7,1)$ & $(0,0.43,1)$ \\
C2 & $(0,0.65,1)$ & $(0,0,0)$ & $(0,33,1)$ & $(0,0.58,1)$ & $(0,0.58,1)$ & $(0,0.63,1)$ & $(0,0.55,1)$ \\
C3 & $(0.25,0.68,1)$ & $(0.5,0.9,1)$ & $(0,0,0)$ & $(0.25,0.68,1)$ & $(0,0.55,1)$ & $(0,0.48,1)$ & $(0,0.55,1)$ \\
C4 & $(0.25,0.83,1)$ & $(0.5,0.88,1)$ & $(0.25,0.78,1)$ & $(0,0,0)$ & $(0,0.68,1)$ & $(0,0.68,1)$ & $(0,0.73,1)$ \\
C5 & $(0,0.55,1)$ & $(0,0.75,1)$ & $(0.25,0.73,1)$ & $(0,0.68,1)$ & $(0,0,0)$ & $(0,0.45,1)$ & $(0,0.65,1)$ \\
C6 & $(0,0.63,1)$ & $(0.5,0.83,1)$ & $(0,0.58,1)$ & $(0,0.58,1)$ & $(0,0.43,1)$ & $(0,0,0)$ & $(0,0.55,1)$ \\
C7 & $(0,0.73,1)$ & $(0.25,0.88,1)$ & $(0.25,0.85,1)$ & $(0.25,0.8,1)$ & $(0,0.63,1)$ & $(0,0.55,1)$ & $(0,0,0)$ \\
P1 & $(0,0.68,1)$ & $(0.5,0.85,1)$ & $(0.5,0.93,1)$ & $(0,0.68,1)$ & $(0,0.45,1)$ & $(0,0.6,1)$ & $(0,0.7,1)$ \\
P2 & $(0.25,0.73,1)$ & $(0.5,0.93,1)$ & $(0.5,0.85,1)$ & $(0.25,0.78,1)$ & $(0.25,0.68,1)$ & $(0.25,0.7,1)$ & $(0.25,0.75,1)$ \\
P3 & $(0.5,0.8,1)$ & $(0.5,0.85,1)$ & $(0,0.75,1)$ & $(0,0.73,1)$ & $(0,0.53,1)$ & $(0.25,0.73,1)$ & $(0,0.7,1)$ \\
P4 & $(0.25,0.73,1)$ & $(0.5,0.88,1)$ & $(0.5,0.8,1)$ & $(0.25,0.78,1)$ & $(0.25,0.65,1)$ & $(0.25,0.75,1)$ & $(0,0.7,1)$ \\
F1 & $(0,0.73,1)$ & $(0,0.68,1)$ & $(0,0.73,1)$ & $(0,0.55,1)$ & $(0,0.65,1)$ & $(0,0.63,1)$ & $(0,0.65,1)$ \\
F2 & $(0,0.85,1)$ & $(0,0.53,1)$ & $(0,0.5,1)$ & $(0,0.48,1)$ & $(0,0.5,1)$ & $(0,0.5,1)$ & $(0,0.53,1)$ \\
\hline
\end{tabular}

TABLE 7. continued.

\begin{tabular}{lllllll}
\hline \hline & P1 & P2 & P3 & P4 & F1 & F2 \\
\hline C1 & $(0,0.53,1)$ & $(0,0.5,1)$ & $(0,0.78,1)$ & $(0,0.65,1)$ & $(0.25,0.85,1)$ & $(0,0.58,1)$ \\
C2 & $(0,0.58,1)$ & $(0.25,0.73,1)$ & $(0.25,0.78,1)$ & $(0.25,0.8,1)$ & $(0.5,0.93,1)$ & $(0,0.73,1)$ \\
C3 & $(0,0.63,1)$ & $(0,0.7,1)$ & $(0,0.6,1)$ & $(0,0.58,1)$ & $(0.5,0.83,1)$ & $(0,0.63,1)$ \\
C4 & $(0.25,0.75,1)$ & $(0.25,0.78,1)$ & $(0.25,0.7,1)$ & $(0.25,0.75,1)$ & $(0.5,0.85,1)$ & $(0,0.75,1)$ \\
C5 & $(0,0.55,1)$ & $(0,0.7,1)$ & $(0,0.65,1)$ & $(0,0.7,1)$ & $(0.25,0.8,1)$ & $(0,0.6,1)$ \\
C6 & $(0,0.55,1)$ & $(0,0.65,1)$ & $(0,0.6,1)$ & $(0,0.63,1)$ & $(0.25,0.73,1)$ & $(0,0.58,1)$ \\
C7 & $(0,0.7,1)$ & $(0.25,0.83,1)$ & $(0,0.75,1)$ & $(0,0.68,1)$ & $(0.25,0.8,1)$ & $(0.25,0.86,1)$ \\
P1 & $(0,0,0)$ & $(0.5,0.88,1)$ & $(0,0.73,1)$ & $(0.5,0.78,1)$ & $(0.25,0.8,1)$ & $(0.25,0.73,1)$ \\
P2 & $(0.25,0.75,1)$ & $(0,0,0)$ & $(0,0.65,1)$ & $(0.25,0.83,1)$ & $(0.25,0.8,1)$ & $(0.25,0.73,1)$ \\
P3 & $(0,0.78,1)$ & $(0.5,0.85,1)$ & $(0,0,0)$ & $(0.25,0.8,1)$ & $(0.25,0.75,1)$ & $(0,0.6,1)$ \\
P4 & $(0,0.8,1)$ & $(0.25,0.88,1)$ & $(0.25,0.75,1)$ & $(0,0,0)$ & $(0,0.73,1)$ & $(0,0.65,1)$ \\
F1 & $(0,0.73,1)$ & $(0,0.75,1)$ & $(0,0.73,1)$ & $(0,0.63,1)$ & $(0,0,0)$ & $(0,0.68,1)$ \\
F2 & $(0,0.48,1)$ & $(0,0.63,1)$ & $(0,0.45,1)$ & $(0,0.48,1)$ & $(0,0.58,1)$ & $(0,0,0)$ \\
\hline
\end{tabular}

Based on Section 4.4 of the proposed method, to identify the better method for integrating the experts' opinions in fuzzy DEMATEL method, one-way MANOVA has been used. For this, the data of Table 10 was loaded into SPSS software. The results have been shown in Tables 11-13.

According to Table 11, the hypothesis $H_{0}$ is rejected and $H_{1}$ is accepted, i.e., the different methods of integrating opinions have significant difference. Table 12 indicates that the dependent variable $D+R$ has caused this deference. Table 13 shows that TM method is a better method for integrating the experts' opinions in this case study.

\section{Conclusion}

Making a suitable decision on critical factors of a supply chain is special interest for specialists. A nonproper evaluation of supply chain factors can incur huge cost to supply chain members. These factors have interactions with each other, and calculating the sum of influence given to and received by each factor can be a suitable measure for the evaluation and ranking of those critical factors. There are different methods for evaluating and ranking of the factors. In fuzzy DEMATEL approach, linguistic opinions and preferences are 
TABLE 8. The aggregation of the experts' judgments with the proposed SM manner in fuzzy DEMATEL.

\begin{tabular}{llllllll}
\hline \hline \multicolumn{2}{l}{$\mathrm{C} 1$} & $\mathrm{C} 2$ & $\mathrm{C} 3$ & $\mathrm{C} 4$ & $\mathrm{C} 5$ & $\mathrm{C} 6$ & $\mathrm{C} 7$ \\
\hline $\mathrm{C} 1$ & $(0,0,0)$ & $(0.68,0.88,1)$ & $(0.05,0.5,0.96)$ & $(0.33,0.63,0.89)$ & $(0.35,0.58,0.89)$ & $(0.38,0.7,0.9)$ & $(0.16,0.43,0.78)$ \\
$\mathrm{C} 2$ & $(0.36,0.65,0.92)$ & $(0,0,0)$ & $(0.07,0.33,0.9)$ & $(0.17,0.58,0.93)$ & $(0.33,0.58,0.94)$ & $(0.31,0.63,1)$ & $(0.31,0.55,0.96)$ \\
C3 & $(0.39,0.68,0.9)$ & $(0.65,0.9,1)$ & $(0,0,0)$ & $(0.34,0.68,0.88)$ & $(0.25,0.55,0.89)$ & $(0.08,0.48,0.78)$ & $(0.33,0.55,0.91)$ \\
C4 & $(0.58,0.83,1)$ & $(0.63,0.88,1)$ & $(0.53,0.78,1)$ & $(0,0,0)$ & $(0.34,0.68,0.97)$ & $(0.38,0.68,0.94)$ & $(0.36,0.73,0.94)$ \\
C5 & $(0.31,0.55,0.91)$ & $(0.44,0.75,1)$ & $(0.44,0.73,0.95)$ & $(0.39,0.68,0.94)$ & $(0,0,0)$ & $(0.05,0.45,0.89)$ & $(0.34,0.65,0.97)$ \\
C6 & $(0.33,0.63,0.89)$ & $(0.58,0.83,1)$ & $(0.31,0.58,0.96)$ & $(0.33,0.58,0.94)$ & $(0,0.43,0.86)$ & $(0,0,0)$ & $(0.33,0.55,0.86)$ \\
C7 & $(0.39,0.73,0.97)$ & $(0.63,0.88,1)$ & $(0.6,0.85,1)$ & $(0.55,0.8,1)$ & $(0.28,0.63,0.96)$ & $(0.25,0.55,0.89)$ & $(0,0,0)$ \\
P1 & $(0.42,0.68,0.97)$ & $(0.6,0.85,1)$ & $(0.68,0.93,1)$ & $(0.42,0.68,0.97)$ & $(0.13,0.45,0.89)$ & $(0.33,0.6,0.89)$ & $(0.41,0.7,0.97)$ \\
P2 & $(0.44,0.73,0.95)$ & $(0.68,0.93,1)$ & $(0.6,0.85,1)$ & $(0.53,0.78,1)$ & $(0.39,0.68,0.9)$ & $(0.38,0.7,0.9)$ & $(0.47,0.75,1)$ \\
P3 & $(0.55,0.8,1)$ & $(0.6,0.85,1)$ & $(0.33,0.75,1)$ & $(0.33,0.73,0.94)$ & $(0.28,0.53,0.88)$ & $(0.44,0.73,0.95)$ & $(0.36,0.7,0.94)$ \\
P4 & $(0.48,0.73,0.98)$ & $(0.63,0.88,1)$ & $(0.55,0.8,1)$ & $(0.53,0.78,1)$ & $(0.36,0.65,0.88)$ & $(0.44,0.75,1)$ & $(0.41,0.7,0.97)$ \\
F1 & $(0.33,0.73,1)$ & $(0.32,0.68,0.92)$ & $(0.33,0.73,0.94)$ & $(0.28,0.55,0.96)$ & $(0.39,0.65,0.94)$ & $(0.31,0.63,0.89)$ & $(0.32,0.65,0.97)$ \\
F2 & $(0.25,0.58,0.88)$ & $(0.3,0.53,0.93)$ & $(0.17,0.5,0.88)$ & $(0.1,0.48,0.93)$ & $(0.06,0.5,0.96)$ & $(0.13,0.5,0.89)$ & $(0.28,0.53,0.88)$ \\
\hline
\end{tabular}

TABLE 8. continued.

\begin{tabular}{lllllll}
\hline \hline & P1 & P2 & P3 & P4 & F1 & F2 \\
\hline C1 & $(0.3,0.53,0.83)$ & $(0.18,0.5,0.84)$ & $(0.53,078,1)$ & $(0.43,0.65,0.97)$ & $(0.6,0.85,1)$ & $(0.33,0.58,0.86)$ \\
C2 & $(0.28,0.58,0.91)$ & $(0.48,0.73,0.98)$ & $(0.53,0.78,1)$ & $(0.55,0.8,1)$ & $(0.68,0.93,1)$ & $(0.33,0.73,0.94)$ \\
C3 & $(0.33,0.63,0.89)$ & $(0.38,0.7,0.94)$ & $(0.33,0.6,0.94)$ & $(0.38,0.58,0.97)$ & $(0.58,0.83,1)$ & $(0.4,0.63,0.94)$ \\
C4 & $(0.39,0.75,1)$ & $(0.53,0.78,1)$ & $(0.42,0.7,0.93)$ & $(0.44,0.75,1)$ & $(0.6,0.85,1)$ & $(0.44,0.75,1)$ \\
C5 & $(0.33,0.55,0.96)$ & $(0.41,0.7,0.97)$ & $(0.4,0.65,0.94)$ & $(0.38,0.7,0.94)$ & $(0.55,0.8,1)$ & $(0.38,0.6,0.92)$ \\
C6 & $(0.33,0.55,0.91)$ & $(0.4,0.65,0.94)$ & $(0.33,0.6,0.89)$ & $(0.31,0.63,0.94)$ & $(0.44,0.73,0.95)$ & $(0.31,0.58,0.91)$ \\
C7 & $(0.41,0.7,0.97)$ & $(0.58,0.83,1)$ & $(0.39,0.75,1)$ & $(0.39,0.68,0.94)$ & $(0.55,0.8,1)$ & $(0.43,0.68,0.93)$ \\
P1 & $(0,0,0)$ & $(0.63,0.88,1)$ & $(0.39,0.73,0.97)$ & $(0.53,0.78,1)$ & $(0.55,0.8,1)$ & $(0.44,0.73,0.95)$ \\
P2 & $(0.47,0.75,1)$ & $(0,0,0)$ & $(0.39,0.65,0.94)$ & $(0.58,0.83,1)$ & $(0.55,0.8,1)$ & $(0.44,0.73,0.95)$ \\
P3 & $(0.53,0.78,1)$ & $(0.6,0.85,1)$ & $(0,0,0)$ & $(0.55,0.8,1)$ & $(0.44,0.75,1)$ & $(0.33,0.6,0.94)$ \\
P4 & $(0.55,0.8,1)$ & $(0.63,0.88,1)$ & $(0.44,0.75,1)$ & $(0,0,0)$ & $(0.33,0.73,0.94)$ & $(0.36,0.65,0.92)$ \\
F1 & $(0.44,0.73,1)$ & $(0.38,0.75,1)$ & $(0.33,0.73,0.94)$ & $(0.36,0.63,0.92)$ & $(0,0,0)$ & $(0.25,0.68,0.94)$ \\
F2 & $(0,0.48,1)$ & $(0.38,0.63,0.92)$ & $(0.08,0.45,0.81)$ & $(0.19,0.48,0.78)$ & $(0.33,0.58,1)$ & $(0,0,0)$ \\
\hline
\end{tabular}

TABLE 9. The aggregation of the experts' judgments with the proposed TM manner in fuzzy DEMATEL.

\begin{tabular}{llllllll}
\hline \hline \multicolumn{2}{l}{ C1 } & C2 & C3 & C4 & C5 & C6 & C7 \\
\hline C1 & $(0,0,0)$ & $(0.48,0.88,0.88)$ & $(0,0.5,1)$ & $(0,0.63,1)$ & $(0.05,0.58,1)$ & $(0.11,0.7,1)$ & $(0,0.43,1)$ \\
C2 & $(0.02,0.65,1)$ & $(0,0,0)$ & $(0,0.33,1)$ & $(0,0.58,1)$ & $(0,0.58,1)$ & $(0,0.63,1)$ & $(0,0.55,1)$ \\
C3 & $(0.17,0.68,1)$ & $(0.51,0.0,0.9)$ & $(0,0,0)$ & $(0.06,0.68,1)$ & $(0,0.55,1)$ & $(0,0.48,1)$ & $(0,0.55,1)$ \\
C4 & $(0.21,0.83,1)$ & $(0.48,0.88,0.88)$ & $(0.35,0.78,1)$ & $(0,0,0)$ & $(0,0.68,1)$ & $(0,0.68,1)$ & $(0,0.73,1)$ \\
C5 & $(0,0.55,1)$ & $(0.14,0.75,1)$ & $(0.3,0.73,1)$ & $(0.06,0.68,1)$ & $(0,0,0)$ & $(0,0.45,1)$ & $(0,0.65,1)$ \\
C6 & $(0,0.63,1)$ & $(0.46,0.83,0.83)$ & $(0,0.58,1)$ & $(0,0.58,1)$ & $(0,0.43,1)$ & $(0,0,0)$ & $(0.04,0.55,1)$ \\
C7 & $(0.02,0.73,1)$ & $(0.34,0.88,1)$ & $(0.33,0.85,1)$ & $(0.33,0.8,1)$ & $(0,0.63,1)$ & $(0,0.55,1)$ & $(0,0,0)$ \\
P1 & $(0.08,0.68,1)$ & $(0.46,0.85,0.85)$ & $(0.56,0.93,0.93)$ & $(0.08,0.68,1)$ & $(0,0.45,1)$ & $(0,0.6,1)$ & $(0.04,0.7,1)$ \\
P2 & $(0.3,0.73,1)$ & $(0.56,0.93,0.93)$ & $(0.46,0.85,0.85)$ & $(0.35,0.78,1)$ & $(0.17,0.68,1)$ & $(0.11,0.7,1)$ & $(0.4,0.75,0.99)$ \\
P3 & $(0.48,0.8,0.8)$ & $(0.46,0.85,0.85)$ & $(0,0.75,1)$ & $(0,0.73,1)$ & $(0,0.53,1)$ & $(0,0.73,1)$ & $(0,0.7,1)$ \\
P4 & $(0.49,0.73,0.96)$ & $(0.48,0.88,0.88)$ & $(0.48,0.8,0.8)$ & $(0.22,0.78,1)$ & $(0.13,0.65,1)$ & $(0.25,0.75,1)$ & $(0.04,0.7,1)$ \\
F1 & $(0,0.73,1)$ & $(0,0.68,1)$ & $(0,0.73,1)$ & $(0,0.55,1)$ & $(0.03,0.65,1)$ & $(0,0.63,1)$ & $(0,0.65,1)$ \\
F2 & $(0,0.58,1)$ & $(0,0.53,1)$ & $(0,0.5,1)$ & $(0,0.48,1)$ & $(0,0.5,1)$ & $(0,0.5,1)$ & $(0,0.53,1)$ \\
\hline
\end{tabular}


TABLE 9. continued.

\begin{tabular}{lllllll}
\hline \hline & $\mathrm{P} 1$ & $\mathrm{P} 2$ & $\mathrm{P} 3$ & $\mathrm{P} 4$ & $\mathrm{~F} 1$ & $\mathrm{~F} 2$ \\
\hline C1 & $(0.05,0.53,1)$ & $(0,0.5,1)$ & $(0.12,0.78,1)$ & $(0.14,0.65,1)$ & $(0.33,0.85,1)$ & $(0.07,0.58,1)$ \\
C2 & $(0,0.58,1)$ & $(0.49,0.73,0.96)$ & $(0.22,0.78,1)$ & $(0.21,0.8,1)$ & $(0.65,0.93,0.93)$ & $(0,0.73,1)$ \\
C3 & $(0,0.63,1)$ & $(0.01,0.7,1)$ & $(0,0.6,1)$ & $(0,0.58,1)$ & $(0.64,0.83,0.83)$ & $(0.1,0.63,1)$ \\
C4 & $(0.14,0.75,1)$ & $(0.22,0.78,1)$ & $(0.23,0.7,1)$ & $(0.25,0.75,1)$ & $(0.46,0.85,0.85)$ & $(0.14,0.75,1)$ \\
C5 & $(0,0.55,1)$ & $(0.04,0.7,1)$ & $(0.13,0.65,1)$ & $(0.01,0.7,1)$ & $(0.2,0.8,1)$ & $(0.07,0.6,1)$ \\
C6 & $(0,0.55,1)$ & $(0.13,0.65,1)$ & $(0,0.6,1)$ & $(0,0.63,1)$ & $(0.3,0.73,1)$ & $(0,0.58,1)$ \\
C7 & $(0.04,0.7,1)$ & $(0.32,0.83,1)$ & $(0.04,0.75,1)$ & $(0.06,0.68,1)$ & $(0.33,0.8,1)$ & $(0.31,0.68,1)$ \\
P1 & $(0,0,0)$ & $(0.48,0.88,0.88)$ & $(0.02,0.73,1)$ & $(0.35,0.78,1)$ & $(0.33,0.8,1)$ & $(0.3,0.73,1)$ \\
P2 & $(0.4,0.75,0.99)$ & $(0,0,0)$ & $(0.03,0.65,1)$ & $(0.32,0.83,1)$ & $(0.33,0.8,1)$ & $(0.3,0.73,1)$ \\
P3 & $(0.03,0.78,1)$ & $(0.46,0.85,0.85)$ & $(0,0,0)$ & $(0.33,0.8,1)$ & $(0.25,0.75,1)$ & $(0,0.6,1)$ \\
P4 & $(0.03,0.8,1)$ & $(0.34,0.88,1)$ & $(0.25,0.75,1)$ & $(0,0,0)$ & $(0,0.73,1)$ & $(0.02,0.65,1)$ \\
F1 & $(0.11,0.73,1)$ & $(0,0.75,1)$ & $(0,0.73,1)$ & $(0,0.63,1)$ & $(0,0,0)$ & $(0,0.68,1)$ \\
F2 & $(0,0.48,1)$ & $(0.09,0.63,1)$ & $(0,0.45,1)$ & $(0,0.48,1)$ & $(0,0.58,1)$ & $(0,0,0)$ \\
\hline
\end{tabular}

TABle 10. The Fuzzy DEMATEL outputs with regard to different methods of aggregating the experts' judgments.

\begin{tabular}{lrrrrrr}
\hline \multirow{2}{*}{ Factors } & \multicolumn{6}{c}{ Aggregation method } \\
\cline { 2 - 7 } & \multicolumn{2}{c}{ CM } & \multicolumn{2}{c}{ SM } \\
\cline { 2 - 7 } & $D+R$ & $D-R$ & $D+R$ & $D-R$ & $D+R$ & \multicolumn{1}{c}{$D-R$} \\
\hline C1 & 0.520 & -0.034 & 0.948 & -0.042 & 2.507 & 0.014 \\
C2 & 0.585 & -0.093 & 1.051 & -0.065 & 2.396 & 0.147 \\
C3 & 0.526 & -0.018 & 0.976 & -0.050 & 2.449 & 0.021 \\
C4 & 0.566 & 0.059 & 1.027 & 0.051 & 2.539 & -0.036 \\
C5 & 0.473 & 0.044 & 0.935 & 0.048 & 2.558 & 0.012 \\
C6 & 0.472 & -0.001 & 0.907 & 0.008 & 2.526 & -0.035 \\
C7 & 0.536 & 0.062 & 0.994 & 0.062 & 2.578 & 0.023 \\
P1 & 0.550 & 0.046 & 1.016 & 0.029 & 2.519 & -0.051 \\
P2 & 0.617 & 0.019 & 1.050 & 0.009 & 2.501 & 0.018 \\
P3 & 0.567 & 0.030 & 1.016 & 0.034 & 2.498 & -0.088 \\
P4 & 0.586 & 0.034 & 1.032 & 0.030 & 2.529 & -0.060 \\
F1 & 0.579 & -0.071 & 1.045 & -0.062 & 2.523 & 0.057 \\
F2 & 0.450 & -0.078 & 0.903 & -0.051 & 2.551 & -0.022 \\
\hline
\end{tabular}

used, and usually, the arithmetic mean is applied for the integration of experts' opinions. However, this mean is drastically sensitive to outliers and makes considerable error. Thus, in this paper, we proposed a statistical-based method for identifying the appropriate method for the integration of experts' opinions. For this, the outputs of fuzzy DEMATEL $(D+R$ and $D-R)$ were evaluated considering the data input method. Since there are two dependent variables $D+R$ and $D-R$ in relation to the independent input method, we used one-way MANOVA for our analysis. As a case study, we considered the data of Mahmoudabad training center in Iran. The results showed that the TM method was better than other methods for integrating the experts' opinions. 
TABLE 11. Multivariate tests ${ }^{a}$.

\begin{tabular}{|c|c|c|c|c|c|c|c|c|c|}
\hline & Effect & Value & $F$ & $\begin{array}{l}\text { Hypothesis } \\
\text { df }\end{array}$ & $\begin{array}{l}\text { Error } \\
\text { df }\end{array}$ & Sig. & $\begin{array}{l}\text { Partial eta } \\
\text { squared }\end{array}$ & $\begin{array}{l}\text { Noncent. } \\
\text { parameter }\end{array}$ & $\begin{array}{l}\text { Observed } \\
\text { power }^{d}\end{array}$ \\
\hline \multirow[t]{5}{*}{ Intercept } & Pillai's Trace & 0.999 & $13692.771^{b}$ & 2.000 & 35.000 & 0.000 & 0.999 & 27385.541 & 1.000 \\
\hline & Wilks' & 0.001 & $13692.771^{b}$ & 2.000 & 35.000 & 0.000 & 0.999 & 27385.541 & 1.000 \\
\hline & Lambda & & & & & & & & \\
\hline & $\begin{array}{l}\text { Hotelling's } \\
\text { Trace }\end{array}$ & 782.444 & $13692.771^{b}$ & 2.000 & 35.000 & 0.000 & 0.999 & 27385.541 & 1.000 \\
\hline & $\begin{array}{l}\text { Roy's Largest } \\
\text { Root }\end{array}$ & 782.444 & $13692.771^{b}$ & 2.000 & 35.000 & 0.000 & 0.999 & 27385.541 & 1.000 \\
\hline \multirow[t]{4}{*}{ Way } & Pillai's Trace & 0.997 & 17.883 & 4.000 & 72.000 & 0.000 & 0.498 & 71.533 & 1.000 \\
\hline & $\begin{array}{l}\text { Wilks' } \\
\text { Lambda }\end{array}$ & 0.003 & $289.295^{b}$ & 4.000 & 70.000 & 0.000 & 0.943 & 1157.180 & 1.000 \\
\hline & $\begin{array}{l}\text { Hotelling's } \\
\text { Trace }\end{array}$ & 306.341 & 2603.895 & 4.000 & 68.000 & 0.000 & 0.994 & 10415.578 & 1.000 \\
\hline & $\begin{array}{l}\text { Roy's Largest } \\
\text { Root }\end{array}$ & 306.341 & $5514.130^{c}$ & 2.000 & 36.000 & 0.000 & 0.997 & 11028.259 & 1.000 \\
\hline
\end{tabular}

Notes. ${ }^{(a)}$ Design: Intercept + Way. ${ }^{(b)}$ Exact statistic. ${ }^{(c)}$ The statistic is an upper bound on $F$ that yields a lower bound on the significance level. ${ }^{(d)}$ Computed using alpha $=0.05$.

TABLE 12. Tests of between-subjects effects.

\begin{tabular}{|c|c|c|c|c|c|c|c|c|c|}
\hline Source & $\begin{array}{l}\text { Dependent } \\
\text { variable }\end{array}$ & $\begin{array}{l}\text { Type III } \\
\text { sum of squares }\end{array}$ & $\mathrm{df}$ & $\begin{array}{l}\text { Mean } \\
\text { square }\end{array}$ & $F$ & Sig. & $\begin{array}{l}\text { Partial eta } \\
\text { squared }\end{array}$ & $\begin{array}{l}\text { Noncent. } \\
\text { parameter }\end{array}$ & $\begin{array}{l}\text { Observed } \\
\text { power }^{c}\end{array}$ \\
\hline \multirow[t]{2}{*}{ Corrected model } & $D+R$ & $27.776^{a}$ & 2 & 13.888 & 5419.331 & 0.000 & 0.997 & 10838.661 & 1.000 \\
\hline & $D-R$ & $1.538 \mathrm{E}-7^{b}$ & 2 & $7.692 \mathrm{E}-8$ & 0.000 & 1.000 & 0.000 & 0.000 & 0.050 \\
\hline \multirow[t]{2}{*}{ Intercept } & $D+R$ & 70.945 & 1 & 70.945 & 27683.832 & 0.000 & 0.999 & 27683.832 & 1.000 \\
\hline & $D-R$ & 0.000 & 1 & 0.000 & 0.000 & 1.000 & 0.000 & 0.000 & 0.050 \\
\hline \multirow[t]{2}{*}{ Way } & $D+R$ & 27.776 & 2 & 13.888 & 5419.331 & 0.000 & 0.997 & 10838.661 & 1.000 \\
\hline & $D-R$ & $1.538 \mathrm{E}-7$ & 2 & $7.692 \mathrm{E}-8$ & 0.000 & 1.000 & 0.000 & 0.000 & 0.050 \\
\hline \multirow[t]{2}{*}{ Error } & $D+R$ & 0.092 & 36 & 0.003 & & & & & \\
\hline & $D-R$ & 0.105 & 36 & 0.003 & & & & & \\
\hline \multirow[t]{2}{*}{ Total } & $D+R$ & 98.814 & 39 & & & & & & \\
\hline & $D-R$ & 0.105 & 39 & & & & & & \\
\hline \multirow[t]{2}{*}{ Corrected total } & $D+R$ & 27.868 & 38 & & & & & & \\
\hline & $D-R$ & 0.105 & 38 & & & & & & \\
\hline
\end{tabular}

Notes. ${ }^{(a)} R$ squared $=0.997$ (Adjusted $R$ squared $\left.=0.997\right) .{ }^{(b)} R$ squared $=0.000$ (Adjusted $R$ squared $=-0.056$ ). ${ }^{(c)}$ Computed using alpha $=0.05$. 
TABLE 13. Multiple comparisons.

\begin{tabular}{|c|c|c|c|c|c|c|c|}
\hline \multicolumn{8}{|c|}{ Tukey HSD } \\
\hline \multirow{2}{*}{$\begin{array}{l}\text { Dependent } \\
\text { variable }\end{array}$} & \multirow{2}{*}{$\begin{array}{l}(I) \text { aggregating of } \\
\text { experts' judgments method }\end{array}$} & \multirow{2}{*}{$\begin{array}{l}(J) \text { aggregating of } \\
\text { experts' judgments method }\end{array}$} & \multirow{2}{*}{$\begin{array}{l}\text { Mean difference } \\
(I-J)\end{array}$} & \multirow{2}{*}{$\begin{array}{l}\text { Std. } \\
\text { error }\end{array}$} & \multirow[t]{2}{*}{ Sig. } & \multicolumn{2}{|c|}{$95 \%$ confidence interval } \\
\hline & & & & & & Lower bound & Upper bound \\
\hline \multirow[t]{6}{*}{$D+R$} & \multirow[t]{2}{*}{$\mathrm{CM}$} & SM & $-0.45177^{*}$ & 0.019856 & 0.000 & -0.50030 & -0.40324 \\
\hline & & $\mathrm{TM}$ & $-1.97285^{*}$ & 0.019856 & 0.000 & -2.02138 & -1.92431 \\
\hline & \multirow[t]{2}{*}{ SM } & $\mathrm{CM}$ & $0.45177^{*}$ & 0.019856 & 0.000 & 0.40324 & 0.50030 \\
\hline & & $\mathrm{TM}$ & $-1.52108^{*}$ & 0.019856 & 0.000 & -1.56961 & -1.47254 \\
\hline & \multirow[t]{2}{*}{ TM } & CM & $1.97285^{*}$ & 0.019856 & 0.000 & 1.92431 & 2.02138 \\
\hline & & SM & $1.52108^{*}$ & 0.019856 & 0.000 & 1.47254 & 1.56961 \\
\hline \multirow[t]{6}{*}{$D-R$} & \multirow[t]{2}{*}{$\mathrm{CM}$} & SM & -0.00015 & 0.021205 & 1.000 & -0.05198 & 0.05168 \\
\hline & & TM & -0.00008 & 0.021205 & 1.000 & -0.05191 & 0.05175 \\
\hline & \multirow[t]{2}{*}{ SM } & $\mathrm{CM}$ & 0.00015 & 0.021205 & 1.000 & -0.05168 & 0.05198 \\
\hline & & TM & 0.00008 & 0.021205 & 1.000 & -0.05175 & 0.05191 \\
\hline & \multirow[t]{2}{*}{$\mathrm{TM}$} & $\mathrm{CM}$ & 0.00008 & 0.021205 & 1.000 & -0.05175 & 0.05191 \\
\hline & & SM & -0.00008 & 0.021205 & 1.000 & -0.05191 & 0.05175 \\
\hline
\end{tabular}

Notes. Based on observed means. The error term is Mean Square (Error) $=0.003{ }^{\left({ }^{*}\right)}$ The mean difference is significant at the 0.05 level.

\section{REFERENCES}

[1] N.S. Abarqhouei, H. Hosseini Nasab and M.B. Fakhrzad, Design of the evaluation model for total ergonomics interventions with fuzzy approach. Sci. J. Pure Appl. Sci. 1 (2012) 119-129.

[2] M.I. Abubakar and Q. Wang, Key human factors and their effects on human centered assembly performance. Int. J. Ind. Ergon. 69 (2019) 48-57.

[3] M. Ahmadifard, F. Sadenejad, I. Mohammadi and K. Aramesh, Forecasting stock market return using ANFIS: the case of Tehran Stock Exchange. Int. J. Adv. Stud. Humanit. Soc. Sci. 1 (2013) 452-459.

[4] E. Akyuz and E. Celik, A fuzzy dematel method to evaluate critical operational hazards during gas freeing process in crude oil tankers. J. Loss Prev. Process Ind. 38 (2015) 243-253.

[5] A. Bavafa, A. Mahdiyar and A.K. Marsono, Identifying and assessing the critical factors for effective implementation of safety programs in construction projects. Saf. Sci. 106 (2018) 47-56.

[6] S. Chirra and D. Kumar, Evaluation of supply chain flexibility in automobile industry with fuzzy DEMATEL Approach. Global J. Flexible Syst. Manage. 19 (2018) 305-319.

[7] Y.W. Du and W. Zhou, New improved DEMATEL method based on both subjective experience and objective data. Eng. App. Artif. Intell. 83 (2019) 57-71.

[8] A. Ebrahimy Zade and M.B. Fakhrzad, A dynamic genetic algorithm for solving a single machine scheduling problem with periodic maintenance. Int. Scholarly Res. Not. 42 (2013) 4397-4409.

[9] A.N. Esfahani, V.F. Sarand and A. Arian, Explain the impact of organizational factors affecting food safety performance using fuzzy dematel. Int. J. Manag. Sci. 5 (2015) 531-543.

[10] R. Eslamipoor, M.B. Fakhrzad and Y. Zare Mehrjerdi, A new robust optimization model under uncertainty for new and remanufactured products. Int. J. Manage. Sci. Eng. Manage. 10 (2015) 137-142.

[11] M.B. Fakhrzad, A. Sadeghieh and L. Emami, A new multi-objective job shop scheduling with setup times using a hybrid genetic algorithm. Int. J. Eng.-Trans. B: App. 26 (2012) 207.

[12] A. Gabus and E. Fontela, Perceptions of the World Problem Antique: Communication Procedure, Communicating with Those Bearing Collective Responsibility (DEMATEL Report No. 1). Battelle Geneva Research Centre, Geneva (1973).

[13] G. George-Ufot, Y. Qu and I.J. Orji, Sustainable lifestyle factors influencing industries' electric consumption patterns using Fuzzy logic and DEMATEL: the Nigerian perspective. J. Cleaner Prod. 162 (2017) 624-634.

[14] K. Govindan, R. Khodaverdi and A. Vafadarnikjoo, Intuitionistic fuzzy based DEMATEL method for developing green practices and performances in a green supply chain. Expert Syst. Appl. 42 (2015) 7207-7220.

[15] M. Gul, A review of occupational health and safety risk assessment approaches based on multi-criteria decision-making methods and their fuzzy versions. Hum. Ecol. Risk Assess. Int. J. 24 (2018) 1723-1760.

[16] M. Gul, Emergency department ergonomic design evaluation: a case study using fuzzy DEMATEL-focused two-stage methodology. Health Policy Technol. 8 (2019) 365-376.

[17] S.M. Hatefi and J. Tamošaitienè, An integrated fuzzy DEMATEL-fuzzy ANP model for evaluating construction projects by considering interrelationships among risk factors. J. Civ. Eng. Manag. 25 (2019) 114-131.

[18] J.S. Jeong and A. Ramírez-Gomez, Development of a web graphic model with fuzzy-decision-making trial and evaluation laboratory/multi-criteria-spatial decision support system (F-DEMATEL/MC-SDSS) for sustainable planning and construction of rural housings. J. Cleaner Prod. 199 (2018) 584-592. 
[19] J.S. Jeong, L. García-Moruno and J. Hernandez-Blanco, Planning of rural housings in reservoir areas under (mass) tourism based on a fuzzy DEMATEL-GIS/MCDA hybrid and participatory method for Alange, Spain. Habitat Int. 57 (2016) $143-153$.

[20] Ö. Kabak, F. Ülengin, B. Çekyay, Ş. Önsel and Ö. Özaydın, Critical success factors for the iron and steel industry in Turkey: a fuzzy DEMATEL approach. Int. J. Fuzzy Syst. 18 (2016) 523-536.

[21] E.G. Kavilal, S.P. Venkatesan and K.D. Harsh Kumar, An integrated fuzzy approach for prioritizing supply chain complexity drivers of an Indian mining equipment manufacturer. Res. Policy 51 (2017) 204-218.

[22] Y. Li, Y. Hu, X. Zhang, Y. Deng and S. Mahadevan, An evidential DEMATEL method to identify critical success factors in emergency management. Appl. Soft Comput. 22 (2014) 504-510.

[23] K.P. Lin, M.L. Tseng and P.F. Pai, Sustainable supply chain management using approximate fuzzy DEMATEL method. Resour. Conserv. Recycl. 128 (2018) 134-142.

[24] H.C. Liu, J.X. You, C. Lu and Y.Z. Chen, Evaluating health-care waste treatment technologies using a hybrid multi-criteria decision making model. Renew. Sustain. Energy Rev. 41 (2015) 932-942.

[25] A. Mahdiyar, S. Tabatabaee, A. Abdullah and A. Marto, Identifying and assessing the critical criteria affecting decision-making for green roof type selection. Sustain. Cities Soc. 39 (2018) 772-783.

[26] S. Mahmoudi, A. Jalali, M. Ahmadi, P. Abasi and N. Salari, Identifying critical success factors in Heart Failure Self-Care using fuzzy DEMATEL method. Appl. Soft Comput. J. 84 (2019) 105729.

[27] S.K. Mangla, P. Kumar and M.K. Barua, Flexible decision modeling for evaluating the risks in green supply chain using fuzzy AHP and IRP methodologies. Glob J. Flex Syst. Manag. 16 (2015) 19-35.

[28] R.K. Mavi and C. Standing, Critical success factors of sustainable project management in construction: a fuzzy DEMATELANP approach. J. Clean. Prod. 194 (2018) 751-765.

[29] I. Mohammadfam, M. Mirzaei Aliabadi, A.R. Soltanian, M. Tabibzadeh and M. Mahdinia, Investigating interactions among vital variables affecting situation awareness based on Fuzzy DEMATEL method. Int. J. Ind. Ergon. 74 (2019) 102842.

[30] M. Nilashia, S. Samad, A. Abdul Manaf, H. Ahmadi, T.A. Rashid, A. Munshi, W. Almukadi, O. Ibrahim and O.H. Ahmed, Factors influencing medical tourism adoption in Malaysia: a DEMATEL-Fuzzy TOPSIS approach. Comput. Ind. Eng. 137 (2019) 106005.

[31] L.A. Ocampo, T.A.G. Tan and L.A. Sia, Using fuzzy DEMATEL in modeling the causal relationships of the antecedents of organizational citizenship behavior (OCB) in the hospitality industry: a case study in the Philippines. J. Hosp. Tour. Manag. 34 (2018) 11-29.

[32] M.A. Quader, S. Ahmed, R.A.R. Ghazilla and M. Dahari, Evaluation of criteria for $\mathrm{CO}_{2}$ capture and storage in the iron and steel industry using the 2-tuple DEMATEL technique. J. Clean. Prod. 120 (2016) 207-220.

[33] S. Rezaei, M. Aliabadi Farahani and S. Nadarajah, Application of fuzzy DEMATEL in explaining causal relations of intellectual capital indices: a study on Shahid Tondgooyan Petrochemical. Ann. Data. Sci. 3 (2016) 307-319.

[34] N. Sadra Abarqhouei, H. Hosseini Nasab and M.B. Fakhrzad, Macro ergonomics interventions and their impact on productivity and reduction of musculoskeletal disorders: including a case study. Iran Occup. Health 9 (2012) 27-39.

[35] M.A. Shoushtary, H. Hoseini Nasab and M.B. Fakhrzad, Team robot motion planning in dynamics environments using a new hybrid algorithm (honey bee mating optimization-tabu list). Chin. J. Eng. 2014 (2014) 1-8.

[36] S.L. Si, X.Y. You, H.C. Liu and J. Huang, Identifying key performance indicators for holistic hospital management with a modified DEMATEL approach. Int. J. Environ. Res. Public Health 14 (2017) 934.

[37] C.M. Su, D.J. Horng, M.L. Tseng, A.S. Chiu, K.J. Wu and H.P. Chen, Improving sustainable supply chain management using a novel hierarchical grey-DEMATEL approach. J. Clean. Prod. 134 (2016) 469-481.

[38] W.L. Suo, B. Feng and Z.P. Fan, Extension of the DEMATEL method in an uncertain linguistic environment. Soft Comput. 16 (2012) 471-483.

[39] X. Wang, F. Zhou, M.K. Lim, Y. He and L. Li, Sustainable recycling partner selection using fuzzy DEMATEL-AEW- FVIKOR: a case study in small-and-medium enterprises (SMEs). J. Cleaner Prod. 196 (2018) 489-504.

[40] X. Xia, K. Govindan and Q. Zhu, Analyzing internal barriers for automotive parts remanufacturers in China using greyDEMATEL approach. J. Clean Prod. 87 (2015) 811-825.

[41] L.A. Zadeh, Fuzzy sets. Inf. Control 8 (1965) 338-353.

[42] X. Zhou, Y. Shi, X. Deng and Y. Deng, D-DEMATEL: a new method to identify critical success factors in emergency management. Saf. Sci. 91 (2017) 93-104. 


\section{Subscribe to Open (S2O) A fair and sustainable open access model}

This journal is currently published in open access with no charge for authors under a Subscribe-to-Open model (S2O). Open access is the free, immediate, online availability of research articles combined with the rights to use these articles fully in the digital environment.

$\mathrm{S} 2 \mathrm{O}$ is one of the transformative models that aim to move subscription journals to open access. Every year, as long as the minimum amount of subscriptions necessary to sustain the publication of the journal is attained, the content for the year is published in open access.

\section{Ask your library to support open access by subscribing to this $\mathbf{S 2 O}$ journal.}

Please help to maintain this journal in open access! Encourage your library to subscribe or verify its subscription by contacting subscribers@edpsciences.org

We are thankful to our subscribers and sponsors for making it possible to publish the journal in open access, free of charge for authors. More information and list of sponsors: https://www.edpsciences.org/en/maths-s2o-programme 